\title{
Mediated effect of cognitive behavioural therapy on depression outcomes
}

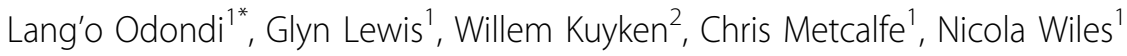 \\ From 2nd Clinical Trials Methodology Conference: Methodology Matters \\ Edinburgh, UK. 18-19 November 2013
}

\section{Introduction}

Understanding how the intervention works is a primary objective in most pragmatic trials. Although good evidence exists for the effectiveness of cognitive behaviour therapy (CBT), there is little evidence presently that cognitive factors, such as dysfunctional attitudes (DAS) or meta-cognitive awareness (MAQ), mediate the effect of CBT on depression outcomes. Standard regression methods adjusting for such mediators produces biased estimates. Using data from the CoBalT trial, we use a 'causal inference' approach to examine the mechanism through which CBT affects depression outcomes.

\section{Methods}

The proportion of the causal effect of CBT on depressive symptoms mediated by DAS and MAQ was estimated (with 95\% confidence intervals) using the 'potential outcomes' approach. The outcome was the Beck Depression Inventory (BDI-II) score at 12 months. Mediators were measured at 6 months post-randomisation.

\section{Results}

Approximately $25 \%$ of the treatment effect observed at 12 months was mediated through changes in DAS $(24 \%$; $95 \%$ CI: 16,41$)$ or MAQ at 6 months $(28 \%$; $95 \%$ CI: 20 , 52 ). This equated, on average, to a one point reduction in the difference in mean BDI-II scores between treatment groups. Sensitivity analyses suggested that a modest degree of 'hidden' confounding $(\rho \cong 0.3$ ) would violate the key assumption of no confounding between any of the three sets of variables.

\section{Conclusion}

Changes in cognitive variables contributed a modest proportion of the observed treatment effect. Causality is

${ }^{1}$ University of Bristol, Bristol, UK

Full list of author information is available at the end of the article intuitively counterfactual and use of potential outcomes provides valid causal inference. However, sensitivity analyses suggested that our findings need to be interpreted with caution as hidden confounding may explain the mediated effect.

\section{Authors' details}

${ }^{1}$ University of Bristol, Bristol, UK. ${ }^{2}$ University of Exeter, Exeter, UK.

Published: 29 November 2013

doi:10.1186/1745-6215-14-S1-P112

Cite this article as: Odondi et al:: Mediated effect of cognitive behavioural therapy on depression outcomes. Trials 2013 14(Suppl 1): P112.
Submit your next manuscript to BioMed Central and take full advantage of:

- Convenient online submission

- Thorough peer review

- No space constraints or color figure charges

- Immediate publication on acceptance

- Inclusion in PubMed, CAS, Scopus and Google Scholar

- Research which is freely available for redistribution
C Biomed Central

\section{Ciomed Central}

(c) 2013 Odondi et al; licensee BioMed Central Ltd. This is an Open Access article distributed under the terms of the Creative Commons Attribution License (http://creativecommons.org/licenses/by/2.0), which permits unrestricted use, distribution, and reproduction in any medium, provided the original work is properly cited. 